\title{
Thigmomorphogenic responses of epiphytic bromeliads to mechanically induced stress
}

\author{
Jessica Y. L. Tay (1) - Gerhard Zotz • Helena J. R. Einzmann
}

Received: 31 May 2021/Accepted: 1 September 2021/Published online: 24 September 2021

(C) The Author(s) 2021

\begin{abstract}
Vascular epiphytes represent almost 10\% of all terrestrial plant diversity. Despite the extensive research on the functional ecology and challenges of epiphytic growth, there is still very little known on how exposure to mechanically induced stress affects the growth and development of epiphytes. Therefore, this study investigated the effect of such mechanical stress on the growth and biomass allocation of epiphytic bromeliads. Juvenile plants of two species were subjected to two types of mechanical stress in the greenhouse-permanent displacement and temporary, recurring mechanical flexing. ANOVAs were used to test possible treatment effects on growth, rootshoot ratio, root diameter, and root area distribution ratio. Contrary to previous studies on herbaceous plants, these bromeliads showed little to no change in root and shoot properties in either species. The root-
\end{abstract}

Communicated by Philip Ladd.

Supplementary Information The online version contains supplementary material available at https://doi.org/10.1007/ s11258-021-01186-6.

J. Y. L. Tay $(\varangle) \cdot$ G. Zotz · H. J. R. Einzmann

Functional Ecology of Plants, Institute of Biology and

Environmental Sciences, University of Oldenburg,

P.O. Box 2503, 26111 Oldenburg, Germany

e-mail: jessica.tay.ying.ling@uni-oldenburg.de

G. Zotz

Smithsonian Tropical Research Institute, 08343-03092 Panama, Republic of Panama shoot ratio increased in disturbed Guzmania lingulata plants, but not in Vriesea sp. Treatment effects on growth were inconsistent: a stress effect on growth was significant only in the first 2 months of the experiment in $G$. lingulata, whilst none of the stress treatments negatively affected growth in Vriesea sp. All disturbed plants showed some degree of curvature on their stems and leaves against the area of stress to obtain an upright position. This was probably related to the maintenance of a functional tank. This study provides quantitative and qualitative data to understand thigmomorphogenic responses of bromeliads to mechanical stress. Future studies could include field surveys to quantify on-site mechanical stresses and the corresponding morphological changes in vascular epiphytes.

Keywords Epiphytes - Wind - Disturbance - Stress · Mechanical stimulation

\section{Introduction}

Mobile animals can respond to stressful events such as predator attacks either by fighting against it or by fleeing to a more favourable environment. For plants, such responses are physically impossible despite being exposed continuously to different stressors like (1) environmental stresses (e.g. Koyro et al. 2012; 
Hasanuzzaman et al. 2013), (2) growth stresses, i.e. increment of dead weight or having an inclined stem (Gril et al. 2017) and (3) mechanically induced nonpermanent stresses when the plants' aerial parts are moved by wind or water currents in flow-dominated habitats (Harder et al. 2006; Read and Stokes 2006). Mechanical loadings on plants can originate from different environmental factors such as wind, rain, ice, snow, as well as during fruits or cone production (Telewski and Pruyn 1998). Wind is by far the most common factor inducing mechanical stress on plants where the aboveground portions of the plant are bent, shaken or flexed (Telewski 1995). Some plants are capable of responding rapidly with specialized cells that are part of the plant's touch-response machinery (Braam 2005); for example, the fast folding leaflets of Mimosa pudica when touched (Malone 1994). In general, plants growing in highly dynamic habitats exposed to potentially high flow velocities can respond with either structural reconfigurations (i.e. Ennos 1999; de Langre et al. 2012; Tay et al. 2021) or a more delayed change in growth (i.e. Stokes et al. 1995; Telewski 1995; Braam 2005). The latter is a well-documented response termed "thigmomorphogenesis", coined by Jaffe (1973) to describe the natural phenomenon that external mechanical stimuli induce gradual physiological and morphological alterations in a plant, which results in tolerance to greater mechanical stresses (Braam 2005; Telewski and Jaffe 1986). For example, the degree of thigmomorphogenesis displayed by Phaseolus vulgaris is positively related to the amount of wind, an arguably adaptive response that minimizes damage by wind gusts (Hunt and Jaffe 1980); the overall alteration in the plant allometry reduces the effective canopy frontal area exposed to wind and hence reduces drag (Rudnicki et al. 2004; Vollsinger et al. 2005).

There has been extensive research since the 1970s to investigate morphological and biomechanical responses in trees and herbaceous plants subjected to mechanical stresses. Such morphological changes are virtually universal in higher plants and include (1) reallocation of biomass between roots and shoots, (2) changes in shoot and root architecture and (3) proportional changes of organs and internal plant structures (Fournier et al. 2006). More specifically, recorded developmental changes in trees and herbaceous plants include an increased tapering of stems, increased radial growth for a shorter stature with thicker, stiffer stem, shorter branches and smaller leaves (Heiligmann and Schneider 1974; Biro et al. 1980; Hunt and Jaffe 1980; Telewski and Jaffe 1986; Gartner 1994). These changes generally result in either an increase in tissue rigidity or higher flexibility to counteract the mechanical perturbations (Biddington 1986). However, adaptive alterations in the root system, as a result of aboveground perturbations, have been studied in less detail (Reubens et al. 2009) and responses were often more varied and complex than the general responses described above for aboveground plant parts. For example, brushing of the shoot resulted in declined root length in cauliflower, lettuce and celery (Biddington and Dearman 1985) but elicited no response in squash (Turgeon and Webb 1971), sunflowers (Beyl and Mitchell 1983) and peas (Akers and Mitchell 1984). For trees, in spite of some general responses (i.e. root/shoot biomass ratio increases in mechanically stressed trees, Stokes et al. 1997), there is much variation related to the specific root system and species (Reubens et al. 2009). For example, Stokes et al. (1995) found that winddisturbed spruce trees had windward roots that were more branched with longer and larger woody tips than leeward roots. Wind-disturbed pines, in turn, had larger root diameter and leeward root tapering was stronger than on the windward side (Watson and Tombleson 2002). Studying the root system is important because it plays a vital role in ensuring anchorage and stability to prevent a plant from falling or getting blown over when subjected to mechanical loading (Ennos 2000).

Even less studied than the typical plant, which is rooted in soil, are plants that are mechanically dependent on other plants, e.g. root climbers and epiphytes, in which attachment to the host tree poses particular challenges. This paper focuses on vascular epiphytes, which-by definition-live on other plants without parasitizing them. Epiphytes take advantage of previously unexploited sites such as tree crotches or branches in the canopy (Zotz 2016) and strong attachment to the host is pivotal to their establishment else they risk falling to the ground where chances of survival are low (Matelson et al. 1993). Ecological research on epiphytes focused mostly on their functional ecology in tropical forests (Zotz et al. 2021, in press), but also on their role in the hydrological cycle, nutrient fluxes and the provision of favourable habitats for other biota (e.g. Coxson and Nadkarni 1995; 
Köhler et al. 2007; Goncalves et al. 2016). The challenges of epiphytic growth due to changing atmospheric conditions are also well studied (e.g. Cervantes et al. 2005; Bader et al. 2009; Zotz et al. 2010; Gehrig-Downie et al. 2011; Wagner and Zotz 2018). Besides high fluctuation in moisture and temperature, life in the treetops also entails greater exposure to mechanical perturbations and loading from wind as compared to terrestrial herbs in the forest understorey (Freiberg 1996; Moore et al. 2018). However, there are limited studies looking at the effect of mechanical stimuli on the growth and development of epiphytes, apart from reports of storm impacts on epiphytes (i.e. Table S2 in Tay et al. 2021).

In a previous study, Tay et al. (2021) determined drag forces on epiphytic bromeliads with longest leaf length of 9-89 $\mathrm{cm}$ in a wind tunnel experiment with wind speeds of up to $22 \mathrm{~m} \mathrm{~s}^{-1}$. Drag forces at the highest wind speed were generally small (i.e. $<0.5 \mathrm{~N}$ in the smallest juveniles and a maximum of $9 \mathrm{~N}$ in one large individual) and did not cause any visible damage to the plants. Results showed that reconfiguration of the plant body effectively reduced relative drag forces on the plant as wind speeds increased, as compared to a rigid plant model. However, such a reduction does not preclude the possibility that mechanically induced stress from wind causes a growth response over time. Therefore, as a first step in this direction, it is essential to achieve a basic understanding of how epiphytes respond to mechanical stress. The objective of this study was to determine if epiphytes respond to mechanical loading in a similar manner as to ground-rooted herbaceous plants. Thigmomorphogenic responses of two bromeliad species, subjected to permanent and temporary recurring mechanical stresses, were documented and we tested if the following responses were also displayed in bromeliads: (1) reduced growth (Goodman and Ennos 1996); (2) increased root/shoot biomass ratio (Gartner 1994); (3) thicker roots (Goodman and Ennos 1998) and (4) higher root biomass allocated to the disturbance-facing side than the opposite side of the stem (Goodman and Ennos 1998).

\section{Materials and methods}

Experimental setup

A greenhouse experiment was designed to examine any thigmomorphogenic response to mechanical stresses on bromeliads. A company in the Netherlands (Corn. Bak. B.V., Assendelft, the Netherlands) provided Guzmania lingulata and Vriesea sp. seedlings. These bromeliads are bark epiphytes that establish themselves on the bark surface of their host trees. In November 2018, 128 plants per species were cleaned and their roots were trimmed. Holes were drilled in untreated wooden poles (Beech, $100 \times 3 \mathrm{~cm} \varnothing$, Hornbach, Oldenburg, Germany), on which each bromeliad was secured with hemp twine [Supplementary material Fig. S1]. Eight individuals per species were attached on each of the 16 poles, i.e. totalling 16 plants per pole. All poles were labelled and each plant on the pole was annotated individually. The poles were attached to a wooden grid with cable ties to prevent the poles from rotating forward due to the weight of the plants. This grid was hung in the greenhouse for the plants to develop roots from December 2018 [Supplementary material Fig. S2]. Climatic conditions in the greenhouse were similar to that of humid tropic conditions, with light values at $70 \mu \mathrm{mol} \mathrm{m} \mathrm{m}^{-2} \mathrm{~s}^{-1}$ in a $12 / 12$-h light/dark photoperiod. The light/dark temperature was $28 / 20{ }^{\circ} \mathrm{C}$, with relative humidity of $80 / 60 \%$, respectively. Plants were watered every other day and fertilized once a week with a liquid fertilizer, WUXAL Super (AGLUKON, Düsseldorf, Germany), diluted to $2 \%$. After 10 months, the newly grown roots were able to support the plants and all supporting twines were removed. During this period, the mortality rate of $G$. lingulata and Vriesea sp. was 3\% and 9\%, respectively. It was not possible to randomize the positions of the samples spatially during this growing phase (and during the experimental phase) because the poles were fastened to the grid and moving the poles might disturb the tentative root attachment. However, light intensity was measured at each pole's positioning and there was no correlation between light intensity and plant growth (overall accumulation in plant length), during this growing phase (ANOVA, $p$ (growth $\sim$ light intensity) $>0.05$ ). 
Permanent and temporary recurring stress experiment

Prior to inducing mechanical stresses to the plants, a single measurement of the longest leaf length was taken for each plant and the root mass was photographed. The poles were divided into two treatment groups, permanent and temporary mechanical stress and a control group (73 plants on five poles). In the permanent stress treatment, plants (93 plants on six poles) were displaced permanently by $20^{\circ}$ from their original upright axis [Supplementary material Fig. S3]. This simulated the situation in which plants are deflected by fallen twigs, branches or other debris but are not severely damaged. A $20^{\circ}$ angle was chosen because it gave maximum possible mechanical stress on the stem and root system without completely dislodging the whole plant at the beginning of the experiment. In the temporary recurring stress treatment, plants (79 plants on five poles) were repeatedly disturbed via repeated flexing of the plants and also by $20^{\circ}$ from their original upright axis. This ensured that the only variable between the permanent and temporary stress treatment was the frequency of applied stress. In previous studies involving flexing or brushing of the plant as a form of disturbance, they were usually done manually by hand (i.e. Gartner 1994). However, manual flexing might introduce some bias in terms of the force applied on the plants. Therefore, since the bromeliads were attached to the branch with their entire body exposed, it was possible to design a custom-made motorized structure to flex all plants at the same time for $1 \mathrm{~min}$ daily in the morning (30 rotations per minute) [Supplementary material Fig. S4, Video 1]. After the disturbance, the plants could return to their original upright position. This flexing scenario simulated daily recurring wind gust pressure on the plants, where the plants are repeatedly deflected but revert to their original position when the wind ceases.

\section{Data acquisition}

The experiment lasted for 6 months from October 2019 to April 2020. To monitor plant growth, the length of the longest leaf was measured monthly.

To identify if there were any stress-related morphological changes in the roots, root mass was photographed at the start and end of the experiment to follow the development of new roots. From those samples where new roots were observed, 10 samples of each species and treatment were randomly chosen for investigation. A $1 \mathrm{~cm}$ portion of 'old' and 'new' root, starting from the part emerging from the stem was collected and preserved in $70 \%$ ethanol. If the selected root was longer than $1 \mathrm{~cm}$, the unused portion was carefully kept in labelled bags for determination of root dry mass later on. The dry weight of $1 \mathrm{~cm}$ of root was negligible and therefore the preserved root portion was not added to the measurement of root dry mass. Root diameter was determined by measuring three separate points along the $1 \mathrm{~cm}$ length and the average taken.

To investigate if mechanically induced stress increased the relative allocation of biomass to the roots, the root-shoot ratio was calculated. To do so, the root mass and stem were separated for each plant and dried at $80{ }^{\circ} \mathrm{C}$ for 3 days. Then the roots and stems were weighted separately for the calculation of the root-shoot ratio.

To investigate whether stress led to an asymmetrical increase in root growth, the root area of attachment of 20 subsamples for each species and each treatment was scanned (Multifunction printer RICOH, MP C2503). In each scan, the point where the stem originated was marked and the root area above the central point, facing the side of the plant that was mechanically disturbed, was defined as 'disturbancefacing' area and root area below the central point as the 'opposite' area [Supplementary material Fig. S5]. The root area was determined using Fiji, a distribution of ImageJ for scientific image analysis (version 1.53c) (Schindelin et al. 2012). The root area ratio of disturbance-facing and opposite side was calculated with these data.

\section{Data analysis}

One-way ANOVAs were used to test the effect of treatments on root-shoot ratio, root diameter and leeward-windward root area ratio. Two-way repeated measures ANOVA was used to simultaneously evaluate the effect of treatment and time variables on the growth of the plants. The assumptions of the ANOVA were checked with the residuals versus fitted plot and the normal Q-Q plot. In case of significance in the one-way ANOVA, a post hoc Tukey test was done. In case of a significant two-way interaction, the effect of 
treatment at each time point and the comparison between treatment groups were evaluated. In case of a non-significant two-way interaction, the main effects were further evaluated for significance with a $T$ test. Boxplots were used to describe the results of the rootshoot ratio and the leeward-windward root area ratio, where the datasets were transformed (logit) to fulfil the assumptions of a normal distribution of an ANOVA. A paired samples $t$ test was used to test if the diameters between the old and new roots within each respective treatment were significantly different. All statistical analyses were performed in $\mathrm{R}$ (version 3.6.3) (R Core Team 2020).

\section{Results}

Growth and biomass distribution

The mortality rates (including plants that fell off during the experiment) over the 6-month experimental period for controls, displaced and flexed plants were
$13 \%, 10 \%$ and $0 \%$ for G. lingulata, respectively; and $26 \%, 11 \%$ and $25 \%$ for Vriesea sp., respectively.

The treatment effects on growth were inconsistent (Fig. 1, Table 1). In G. lingulata, there was a significant two-way interaction between treatment and time $(F(10,320)=3.71$, where the numbers in brackets are the degrees of freedom in the numerator and denominator, respectively, $p<0.001$ ). Therefore, the treatment effect was analysed at each time point. $p$ values were adjusted using the Bonferroni multiple testing correction method. The only significant effect on growth was elicited by the flexing treatment, where plants grew significantly faster than controls in the first month, but more slowly in the third month (pairwise comparison, $p_{\text {adj }}<0.05$; Table 1). For Vriesea sp., there was a non-significant two-way interaction between treatment and time. None of the stress treatments had a negative effect on growth; in fact, the disturbed plants tended to be bigger, although differences to controls were not statistically significant (Fig. 1).

Boxplots were used to describe the results of the root-shoot ratio and the leeward-windward root area

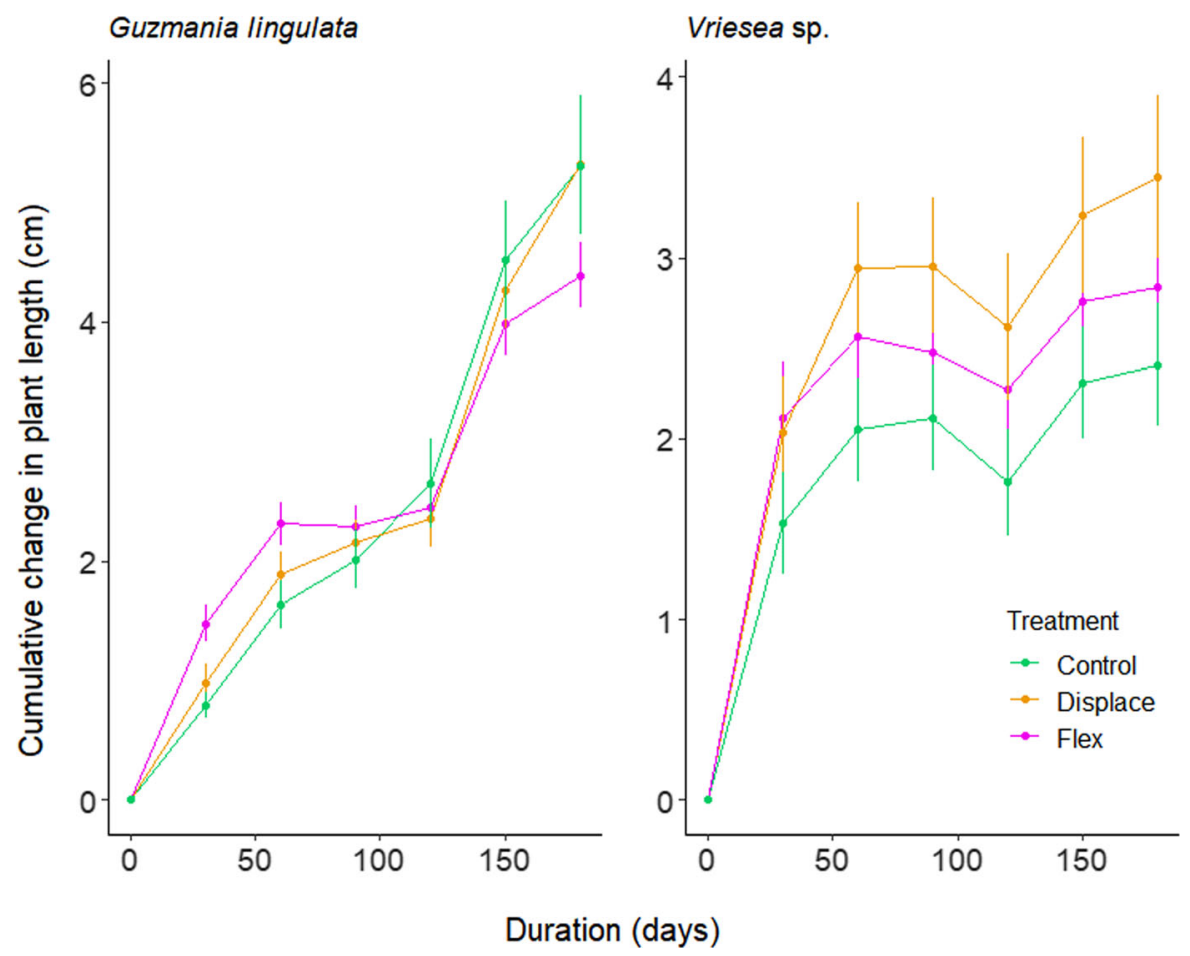

Fig. 1 Mean cumulative changes in the plant length over 180 days for plants receiving different treatments. Error bars represent standard errors 
Table 1 Mean and standard deviation of the change in plant length from the previous month of the stressed and control plants

\begin{tabular}{lllrrrr}
\hline Guzmania lingulata $(\mathrm{cm})$ & \multicolumn{1}{l}{$t=30$} & \multicolumn{1}{l}{$t=60$} & \multicolumn{1}{c}{$t=90$} & \multicolumn{1}{c}{$t=120$} & $t=150$ & $t=180$ \\
\hline Flex & $\mathbf{1 . 5} \pm \mathbf{1 . 0}$ & $0.8 \pm 0.6$ & $\mathbf{0} \pm \mathbf{0 . 5}$ & $0.2 \pm 0.6$ & $1.5 \pm 1.0$ & $0.4 \pm 0.5$ \\
Displace & $1.0 \pm 1.0$ & $0.9 \pm 0.8$ & $0.3 \pm 0.7$ & $0.2 \pm 0.9$ & $1.9 \pm 1.1$ & $1.1 \pm 0.9$ \\
Control & $0.8 \pm 0.6$ & $0.8 \pm 0.8$ & $0.4 \pm 0.8$ & $0.6 \pm 1.0$ & $1.9 \pm 1.2$ & $0.8 \pm 0.8$ \\
Vriesea sp. & & & & & & \\
Flex & $2.1 \pm 1.6$ & $0.5 \pm 0.5$ & $-0.1 \pm 0.3$ & $-0.2 \pm 0.5$ & $0.5 \pm 0.7$ & $0.1 \pm 0.6$ \\
Displace & $2.0 \pm 1.9$ & $0.9 \pm 1.2$ & $0 \pm 0.5$ & $-0.3 \pm 0.7$ & $0.6 \pm 0.7$ & $0.2 \pm 0.6$ \\
Control & $1.5 \pm 1.4$ & $0.5 \pm 0.7$ & $0.1 \pm 0.5$ & $-0.4 \pm 0.8$ & $0.6 \pm 0.7$ & $0.1 \pm 0.8$ \\
\hline
\end{tabular}

Bold values differ significantly from the control (pairwise comparison, $p_{\text {adj }}<0.05$ ), $t$ represents time in days

ratio. All mechanically stressed $G$. lingulata plants had significantly higher root-shoot ratios compared to controls (Tukey HSD, $p$ (Root-shoot ratio Treatment)$<0.001$, Fig. 2). In contrast, the stress treatments did not result in a significant increase in root-shoot ratios in Vriesea sp. (Fig. 2). In neither G. lingulata nor Vriesea sp. did mechanically stressed plants have significantly more roots on the undisturbed side of the plant, compared to the controls (Fig. 3).

For G. lingulata, in all treatments and the controls, the diameter of new roots consistently exceeded that of older roots ( $t$ test, $p<0.001$ ). This suggests that size increase in diameter is unrelated to treatment. In Vriesea sp., however, only the displaced plants

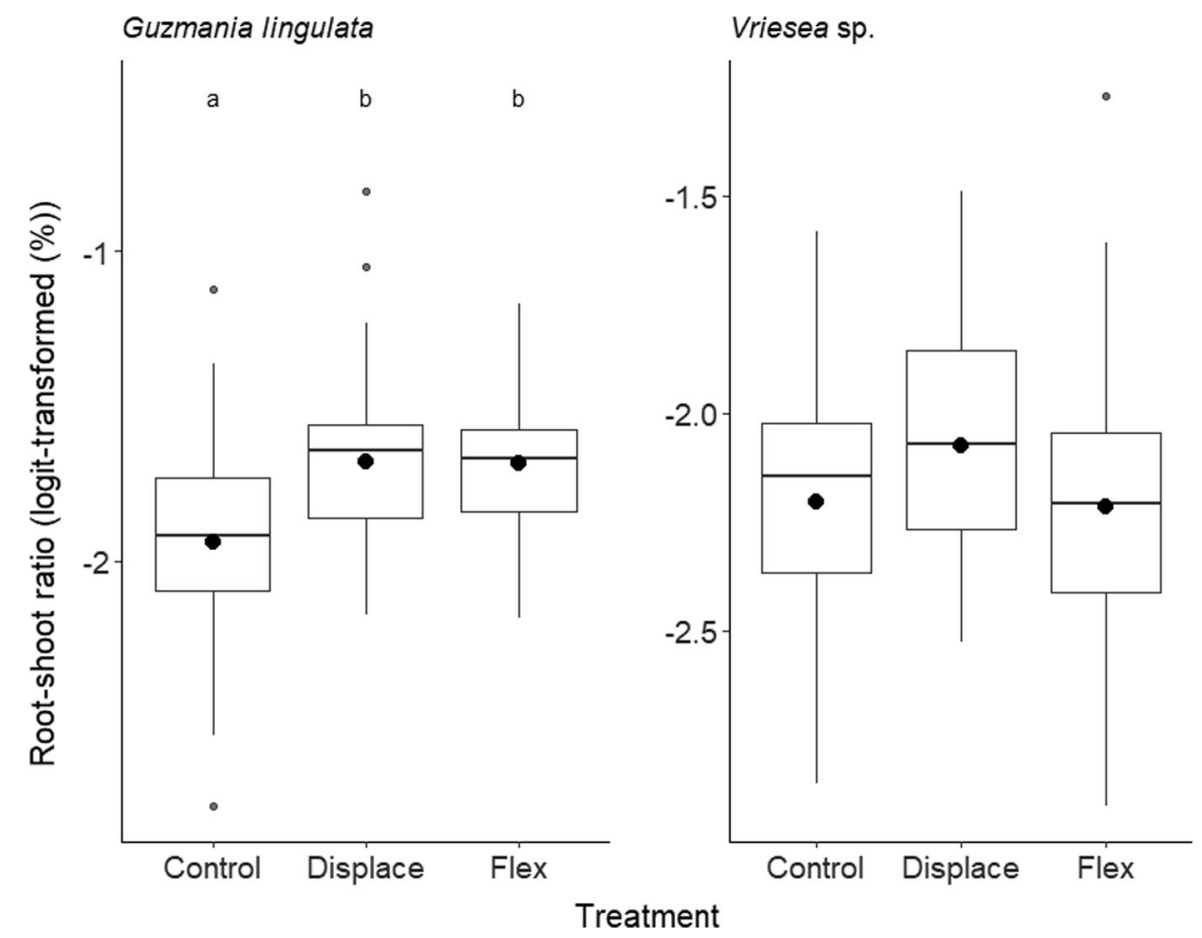

Fig. 2 Root-shoot ratio after 6 months of experimental treatments. The filled black circle marked the mean of each treatment; the horizontal line within the boxplot represented the median and the range of the boxplot was plotted at plus and minus one standard deviation; the vertical lines at the ends of the boxplot represented the range of the dataset; the points outside the boxplot were the outliers. For G. lingulata, all mechanically stressed plants had higher root-shoot ratio than the controls (Tukey HSD, $p_{\text {(Root-shoot ratio } \sim \text { Treatment) }}<0.001$ ). In contrast, root-shoot ratios of the mechanically stressed plants in Vriesea sp. were indistinguishable from those of controls. Different lower-case letters indicate significant differences 

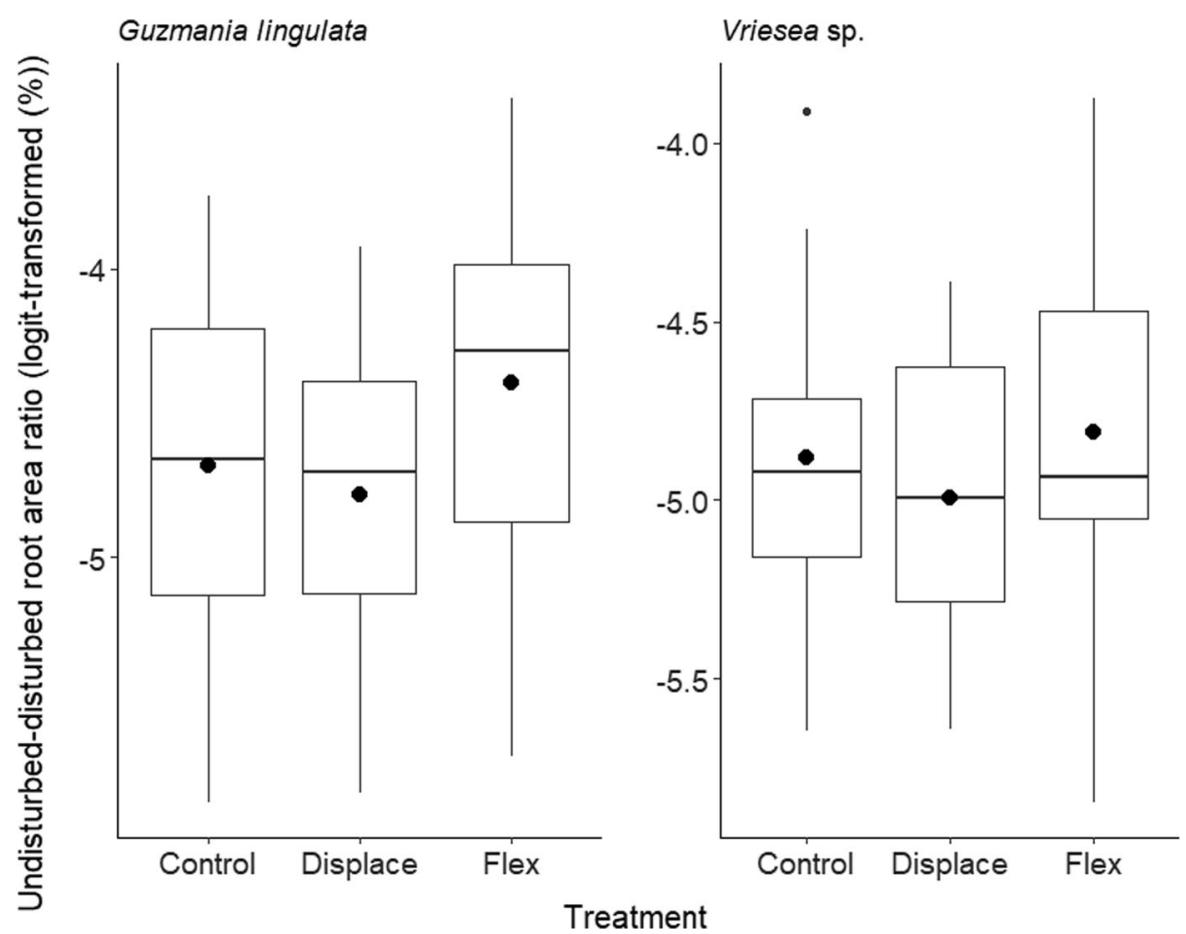

Fig. 3 The root area ratio of disturbance-facing and opposite side of the plants after 6 months of mechanical stress. The filled black circle marked the mean of each treatment; the horizontal line within the boxplot represented the median and the range of the boxplot was plotted at plus and minus one standard

produced significantly thicker new roots ( $t$ test, $p$ (New roots $\sim$ old roots) $<0.05$ ). Again, root diameter of new roots did not differ significantly between mechanically stressed and control plants.

\section{Discussion}

The permanent and temporary recurring mechanical stress applied to the plants in our experiment simulated stress scenarios that an epiphyte may face in its natural habitat, e.g. wind in exposed tree crowns or falling debris deflecting the plants from their upright growth. Surprisingly, there was little to no change in root and shoot properties in either bromeliad species. Our expectations were met in only one case: the root-shoot ratio increased in disturbed $G$. lingulata plants (Fig. 2). We interpret this increased allocation of biomass to roots as a strategy to assure anchorage of the mechanically disturbed plants by increasing the number, the length and/or the diameter of roots, all of which are known to improve stability (Crook and deviation; the vertical lines at the ends of the boxplot represented the range of the dataset; the points outside the boxplot were the outliers. In both species, no mechanically stressed plants had more roots at the undisturbed side as compared to the control

Ennos 1996; Goodman and Ennos 1998). However, this response was not observed in Vriesea sp. (Fig. 2), which does not even allow a cautious conclusion that there is a general thigmomorphogenic response of epiphytes to mechanical stress.

Somewhat surprisingly, growth was not significantly reduced in mechanically disturbed plants (Fig. 1). Only the flexed G. lingulata plants had a response to the onset of stress. Instead of having reduced growth, these plants were growing significantly faster than controls. However, the treatment effect was found only in the first 2 months of the experiment, and it was not observed in the displaced plants, nor in any of the disturbed Vriesea sp. plants. We conclude from this that these bromeliads had a larger safety margin against mechanical stress than anticipated when designing the experiment. This is somewhat unexpected, because from a previous study where bromeliads were subjected to wind in a wind tunnel, plants of similar form and size to those used in this study were observed to be deflected by c. $20^{\circ}$ when subjected to wind speed of $15 \mathrm{~m} \mathrm{~s}^{-1}$ (Tay et al. 
2021, unpubl. data). Mean wind speeds in some tropical lowland forests, under non-storm conditions, were recorded to range from $3.5 \mathrm{~m} \mathrm{~s}^{-1}$ at $60 \mathrm{~m}$ above the ground (Colombia, Baynton et al. 1965) and $2.8 \mathrm{~m} \mathrm{~s}^{-1}$ at $47 \mathrm{~m}$ above the ground (Malaysia, Aoki et al. 1975). Therefore, flexing the plant at $20^{\circ}$ meant that they were already facing pressure from winds that were much higher than the typical mean wind speeds in the lowland forests. Nonetheless, the results imply that either the plants responded quickly to negate the mechanical stress present, since the only reactions were recorded in the first few months of the experiment or that the mechanical stress level was perhaps still insufficient to trigger a significant general thigmomorphogenic response in the bromeliads.

We did not find any significant differences in root diameter in new roots between disturbed and control plants. External mechanical loading on the shoots is usually transmitted to the root system for effective anchorage and stability to counter external abiotic stress (e.g. Coutts 1986; Gartner 1994; Stokes et al. 1995; Telewski 1995; Nicoll and Ray 1996; Stokes and Guitard 1997; Niklas 1999; Fournier et al. 2006). Effective anchorage of a terrestrial plant depends on root architecture (e.g. Warren et al. 1988; Ennos 1993; Crook et al. 1997; Di Iorio et al. 2004; Dupuy et al. 2007) and toppled trees due to anchorage failure usually have relatively low root biomass (Moore and Somerville 1998; Dorval et al. 2016). However, the anchorage function of epiphyte roots differs from plants that root in soil. In the habitat of most epiphytes (at least in the lowlands), there is hardly sufficient substrate material to develop deep, lateral (common) root systems for stable anchorage. In contrast to mistletoe roots, roots of vascular epiphytes do not penetrate the host but achieve attachment by growing in close contact to the surface of the substrate. Therefore, the root-substrate adherence plays a vital role in the attachment of epiphytes to their host (Benzing 1970). Although not rigorously quantified, plants that failed from the mechanical loading within the first 2 months of the experiments had smaller, less dense root system (Tay, pers. obs.).

All plants that were displaced or mechanically flexed showed some degree of curvature of their stems and leaves against the area of stress to regain an upright position (Fig. S3c). This implies that the plants grew to counter the disturbance to achieve the upright position, which is essential to maintain a functional tank (Zotz and Laube 2005; Zotz et al. 2020). This phenomenon was not surprising as Benzing (1970) observed that other Tillandsia and Vriesea species showed negative, geotropic response in their stems by curling upward after establishing themselves as seedlings on the undersides of small twigs or branches of trees.

This is the first study to provide quantitative and qualitative data on thigmomorphogenic responses of epiphytes to mechanical stress. Although the results of this study showed little responses to mechanical stress, one cannot assume that every experiment aimed at investigating responses from mechanical perturbations will produce similar results. Potocka and Szymanowska-Pułka (2018) reviewed the morphological responses of plant roots to mechanical stress and concluded that whilst there are some commonly reported modifications, factors such as the nature of the species in their habitats, history and magnitude of stress and the properties of individual plants make it challenging to design a universal stress scenario to elicit the same modifications as reported in other studies. Mechanical stress applied to the two species in our study can only approximate the situation of similar bark epiphytes and cannot be representative for other epiphytes in the lowlands, let alone montane forests where epiphytes can also establish themselves in arboreal soils where anchorage is more similar to that of plants in terrestrial soils. Nonetheless, in a field study conducted on Barro Colorado Island, Panama, where juveniles of three bromeliad species were mechanically stressed over 4 months (i.e. displaced permanently by $20^{\circ}$ from their original upright axis) and yielded similar results with no effect on growth in mechanically stressed plants (Tay, unpubl. res.). Hence, assuming that the species used in this study were not exceptional, the results from this study suggest that the mechanical stress imposed by the current experimental design induced little thigmomorphogenic responses. From an ecological point of view, thigmomorphogenic responses can indeed increase the resistance of plants to wind stress, with morphological changes reducing drag and/or increasing the mechanical strength of their stem and root system. However, the biology of vascular epiphytes is clearly different from that of trees and ground-rooted herbaceous plants, especially in terms of how they establish and attach on their hosts. There are few studies on the attachment mechanism and attachment strength of 
epiphytes to their substrate that go beyond the anecdotal (e.g. Johansson 1974; Kernan and Fowler 1995; Thangavelu and Ayyasamy 2017; Yang and Deng 2017). Therefore, this study can only be a first step to provide basic information regarding how external mechanical stress affects epiphytes' growth and development.

In this study, the plants were mechanically stressed with a motorized structure for only $1 \mathrm{~min}$ per day. Whilst this was an improvement for more uniform application of stress, as compared to previous studies, which relied on manual flexing of the plant, it still does not reflect how a plant actually gets disturbed by wind in nature-which acts on the entire plant body and is less uniform. Nonetheless, to observe thigmomorphogenesis in epiphytes, this study does provide a starting point for future investigations. Therefore, if this experiment were to be repeated, the custom-made motorized structure should be programmed to push plants with different intensities and durations, to simulate a more realistic scenario of wind disturbances in the natural habitat. Future studies could use varying degrees of mechanical stresses, as an attempt to determine the stress threshold for vascular epiphytes plants. More field surveys are also essential to quantify external mechanical stresses on-site and any corresponding morphological changes in vascular epiphytes.

Acknowledgements We are grateful to Corn. Bak. (Netherlands) for providing the bromeliad seedlings to make this experiment possible. We also thank Norbert Wagner (Oldenburg) for plant care during the course of the experiment.

Author contributions Conceptualization: [GZ, HE]; Methodology: [JTYL]; Formal analysis and investigation: [JTYL]; Writing-original draft preparation: [JTYL]; Writing-review and editing: [JTYL, GZ, HE]; Funding acquisition: [HE]; Supervision: [GZ, HE].

Funding Open Access funding enabled and organized by Projekt DEAL. This work was supported by a Grant from the German Research Foundation [Grant number El 1092/1-1].

Data availability When the manuscript is accepted for publication, we intend to archive the data in the data repository of the Smithsonian Tropical Research Institute in the figshare archive under a 1-year embargo.

Code availability Not applicable.

\section{Declarations}

Conflict of interest The authors declare that they have no known competing financial interests or personal relationships that could have appeared to influence the work reported in this paper.

Ethical approval Not applicable.

Consent for Publication/Participate All participating authors consent to publication and participation.

Open Access This article is licensed under a Creative Commons Attribution 4.0 International License, which permits use, sharing, adaptation, distribution and reproduction in any medium or format, as long as you give appropriate credit to the original author(s) and the source, provide a link to the Creative Commons licence, and indicate if changes were made. The images or other third party material in this article are included in the article's Creative Commons licence, unless indicated otherwise in a credit line to the material. If material is not included in the article's Creative Commons licence and your intended use is not permitted by statutory regulation or exceeds the permitted use, you will need to obtain permission directly from the copyright holder. To view a copy of this licence, visit http://creativecommons.org/licenses/by/4.0/.

\section{References}

Akers SW, Mitchell CA (1984) Seismic stress effects on vegetative and reproductive development of 'Alaska' pea. Can J Bot 62:2011-2015. https://doi.org/10.1139/b84-273

Aoki M, Yabuki K, Koyama H (1975) Micrometeorology and assessment of primary production of a tropical rain forest in West Malaysia. J Agric Meteorol 31:115-124. https://doi. org/10.2480/agrmet.31.115

Bader MY, Menke G, Zotz G (2009) Pronounced drought tolerance characterizes the early life stages of the epiphytic bromeliad Tillandsia flexuosa. Funct Ecol 23:472-479. https://doi.org/10.1111/j.1365-2435.2009.01547.x

Baynton HW, Biggs WG, Hamilton HL Jr, Sherr PE, Worth JJ (1965) Wind structure in and above a tropical forest. J Appl Meteorol 4:670-675. https://doi.org/10.1175/15200450(1965)004\%3c0670:WSIAAA\%3e2.0.CO;2

Benzing D (1970) Roots in certain species of Tillandsia and Vriesea and their role in the epiphytic environment. Bromeliad Soc Bull 79-84

Beyl C, Mitchell C (1983) Alteration of growth, exudation rate, and endogenous hormone profiles in mechanically dwarfed sunflower. J Am Soc Hort Sci 108:257-262

Biddington NL (1986) The effects of mechanically-induced stress in plants-a review. Plant Growth Regul 4:103-123. https://doi.org/10.1007/BF00025193

Biddington NL, Dearman A (1985) The effect of mechanically induced stress on the growth of cauliflower, lettuce and celery seedlings. Ann Bot 55:109-119 
Biro R, Hunt E Jr, Erner Y, Jaffe M (1980) Thigmomorphogenesis: changes in cell division and elongation in the internodes of mechanically-perturbed or ethrel-treated bean plants. Ann Bot 45:655-664

Braam J (2005) In touch: plant responses to mechanical stimuli. New Phytol 165:373-389. https://doi.org/10.1111/j.14698137.2004.01263.x

Cervantes SE, Graham EA, Andrade JL (2005) Light microhabitats, growth and photosynthesis of an epiphytic bromeliad in a tropical dry forest. Plant Ecol 179:107-118. https://doi.org/10.1007/s11258-004-5802-3

Coutts M (1986) Components of tree stability in Sitka spruce on peaty gley soil. Int J For Res 59:173-197

Coxson D, Nadkarni N (1995) Ecological roles of epiphytes in nutrient cycles of forest ecosystems. In: Lowman MD, Nadkarni NM (eds) Forest canopies. Academic Press, San Diego, pp 495-543

Crook M, Ennos A (1996) The anchorage mechanics of deep rooted larch, Larix europea $\times$ L. japonica. J Exp Bot 47:1509-1517

Crook M, Ennos A, Banks J (1997) The function of buttress roots: a comparative study of the anchorage systems of buttressed (Aglaia and Nephelium ramboutan species) and non-buttressed (Mallotus wrayi) tropical trees. J Exp Bot 48:1703-1716

de Langre E, Gutierrez A, Cossé J (2012) On the scaling of drag reduction by reconfiguration in plants. Comptes Rendus Mécanique 340:35-40. https://doi.org/10.1016/j.crme. 2011.11.005

Di Iorio A, Lasserre B, Scippa GS, Chiatante D (2004) Root system architecture of Quercus pubescens trees growing on different sloping conditions. Ann Bot 95:351-361. https:// doi.org/10.1093/aob/mci033

Dorval AD, Meredieu C, Danjon F (2016) Anchorage failure of young trees in sandy soils is prevented by a rigid central part of the root system with various designs. Ann Bot 118:747-762. https://doi.org/10.1093/aob/mcw098

Dupuy L, Fourcaud T, Stokes A (2007) A numerical investigation into the influence of soil type and root architecture on tree anchorage. In: Stokes A, Spanos I, Norris JE, Cammeraat E (eds) Eco-and ground bio-engineering: the use of vegetation to improve slope stability. Springer, Dordrecht, pp 175-189

Ennos A (1993) The function and formation of buttresses. Trends Ecol Evol 8:350-351. https://doi.org/10.1016/ 0169-5347(93)90217-d

Ennos A (1999) The aerodynamics and hydrodynamics of plants. J Exp Biol 202:3281-3284. https://doi.org/10.1242/ jeb.202.23.3281

Ennos A (2000) The mechanics of root anchorage. Adv Bot Res 33:133-157. 2296(00)33042-7

Fournier M, Stokes A, Coutand C, Fourcaud T, Moulia B (2006) Tree biomechanics and growth strategies in the context of forest functional ecology. In: Herrel A, Speck T, Rowe NP (eds) Ecology and biomechanics-a mechanical approach to the ecology of animals and plants. Taylor \& Francis Group, Boca Raton, pp 1-33

Freiberg M (1996) Spatial distribution of vascular epiphytes on three emergent canopy trees in French Guiana. Biotropica. https://doi.org/10.2307/2389198
Gartner BL (1994) Root biomechanics and whole-plant allocation patterns: responses of tomato plants to stem flexure. J Exp Bot 45:1647-1654. https://doi.org/10.1093/jxb/45. 11.1647

Gehrig-Downie C, Obregón A, Bendix J, Gradstein SR (2011) Epiphyte biomass and canopy microclimate in the tropical lowland cloud forest of French Guiana. Biotropica 43:591-596. https://doi.org/10.1111/j.1744-7429.2010. 00745.x

Goncalves AZ, Oliveira RS, Oliveira PS, Romero GQ (2016) Species-specific effects of ant inhabitants on bromeliad nutrition. PLoS One 11:e0152113. https://doi.org/10.1371/ journal.pone.0152113

Goodman A, Ennos A (1996) A comparative study of the response of the roots and shoots of sunflower and maize to mechanical stimulation. J Exp Bot 47:1499-1507

Goodman A, Ennos A (1998) Responses of the root systems of sunflower and maize to unidirectional stem flexure. Ann Bot 82:347-357. https://doi.org/10.1006/anbo.1998.0693

Gril J, Jullien D, Bardet S, Yamamoto H (2017) Tree growth stress and related problems. J Wood Sci 63:411-432. https://doi.org/10.1007/s10086-017-1639-y

Harder DL, Hurd CL, Speck T (2006) Comparison of mechanical properties of four large, wave-exposed seaweeds. Am J Bot 93:1426-1432. https://doi.org/10.3732/ajb.93.10.1426

Hasanuzzaman M, Nahar K, Gill SS, Fujita M (2013) Drought stress responses in plants, oxidative stress, and antioxidant defense. In: Tuteja N, Gill SS (eds) Climate change and plant abiotic stress tolerance. Wiley, Weinheim, pp 209-250. https://doi.org/10.1002/9783527675265.ch09

Heiligmann R, Schneider G (1974) Effects of wind and soil moisture on black walnut seedlings. For Sci 20:331-335. https://doi.org/10.1093/forestscience/20.4.331

Hunt ER Jr, Jaffe M (1980) Thigmomorphogenesis: the interaction of wind and temperature in the field on the growth of Phaseolus vulgaris L. Ann Bot 45:665-672. https://doi. org/10.1093/oxfordjournals.aob.a085875

Jaffe M (1973) Thigmomorphogenesis: the response of plant growth and development to mechanical stimulation. Planta 114:143-157. https://doi.org/10.1007/BF00387472

Johansson D (1974) Ecology of vascular epiphytes in West African rain forest. Acta Phytogeogr Suec 59:1-136

Kernan C, Fowler N (1995) Differential substrate use by epiphytes in Corcovado National Park, Costa Rica: a source of guild structure. J Ecol 83:65-73. https://doi.org/10.2307/ 2261151

Köhler L, Tobón C, Frumau KA, Bruijnzeel LS (2007) Biomass and water storage dynamics of epiphytes in old-growth and secondary montane cloud forest stands in Costa Rica. Plant Ecol 193:171-184. https://doi.org/10.1007/s11258-0069256-7

Koyro HW, Ahmad P, Geissler N (2012) Abiotic Stress Responses in Plants: An Overview. In: Ahmad P, Prasad M (eds) Environmental Adaptations and Stress Tolerance of Plants in the Era of Climate Change. Springer, New York, NY. pp 1-28. https://doi.org/10.1007/978-1-4614-0815-4_ 1

Malone M (1994) Wound-induced hydraulic signals and stimulus transmission in Mimosa pudica L. New Phytol128:49-56. https://doi.org/10.1111/j.1469-8137.1994. tb03985.x 
Matelson TJ, Nadkarni NM, Longino JT (1993) Longevity of fallen epiphytes in a neotropical montane forest. Ecology 74:265-269

Moore J, Gardiner B, Sellier D (2018) Tree mechanics and wind loading. In: Geitmann A, Gril J (eds) Plant biomechanics: from structure to function at multiple scales. Springer, Cham, pp 79-106. https://doi.org/10.1007/978-3-31979099-2_4

Moore J, Somerville A (1998) Assessing the risk of wind damage to plantation forests in New Zealand. NZ Forestry 43:25-29

Nicoll BC, Ray D (1996) Adaptive growth of tree root systems in response to wind action and site conditions. Tree Physiol 16:891-898. https://doi.org/10.1093/treephys/16.11-12. 891

Niklas K (1999) Variations of the mechanical properties of Acer saccharum roots. J Exp Bot 50:193-200. https://doi.org/10. 1093/jxb/50.331.193

Potocka I, Szymanowska-Pułka J (2018) Morphological responses of plant roots to mechanical stress. Ann Bot 122:711-723. https://doi.org/10.1093/aob/mcy010

R Core Team (2021) R: A language and environment for statistical computing. Vienna, Austria: R foundation for statistical computing. Retrieved from http://www.R-project. org. Accessed 10 Aug 2021

Read J, Stokes A (2006) Plant biomechanics in an ecological context. Am J Bot 93:1546-1565. https://doi.org/10.3732/ ajb.93.10.1546

Reubens B, Pannemans B, Danjon F et al (2009) The effect of mechanical stimulation on root and shoot development of young containerised Quercus robur and Robinia pseudoacacia trees. Trees 23:1213-1228. https://doi.org/10. 1007/s00468-009-0360-x

Rudnicki M, Mitchell SJ, Novak MD (2004) Wind tunnel measurements of crown streamlining and drag relationships for three conifer species. Can J For Res-Revue Canadienne De Recherche Forestiere 34:666-676. https:// doi.org/10.1139/x03-233

Schindelin J, Arganda-Carreras I, Frise E et al (2012) Fiji: an open-source platform for biological-image analysis. Nat Methods 9:676-682. https://doi.org/10.1038/nmeth.2019

Stokes A, Fitter A, Courts M (1995) Responses of young trees to wind and shading: effects on root architecture. J Exp Bot 46:1139-1146

Stokes A, Nicoll BC, Coutts MP, Fitter AH (1997) Responses of young Sitka spruce clones to mechanical perturbation and nutrition: effects on biomass allocation, root development, and resistance to bending. Can $\mathrm{J}$ for Res 27:1049-1057. https://doi.org/10.1139/x97-041

Stokes A, Guitard D (1997) Tree Root Response to Mechanical Stress. In: Altman A, Waisel Y (eds) Biology of root formation and development. Springer, Boston, pp 227-236. https://doi.org/10.1007/978-1-4615-5403-5_45

Tay JYL, Zotz G, Puczylowski J, Einzmann HJR (2021) Go with the flow: the extent of drag reduction as epiphytic bromeliads reorient in wind. PLoS One 16:e0252790. https://doi.org/10.1371/journal.pone.0252790
Telewski F, Jaffe M (1986) Thigmomorphogenesis: field and laboratory studies of Abies fraseri in response to wind or mechanical perturbation. Physiol Plant 66:211-218. https://doi.org/10.1111/j.1399-3054.1986.tb02411.x

Telewski F, Pruyn ML (1998) Thigmomorphogenesis: a dose response to flexing in Ulmus americana seedlings. Tree Physiol 18:65-68

Telewski F (1995) Wind-induced physiological and developmental responses in trees. In: Grace J, Coutts MP (eds) Wind and trees. Cambridge University Press, Cambridge, pp 237-263. https://doi.org/10.1017/CBO9780511600425. 015

Thangavelu M, Ayyasamy K (2017) Comparative anatomy of aerial and substrate roots of Acampe praemorsa (Rox.) Blatt. \& McCann. Flora 226:17-28

Turgeon R, Webb J (1971) Growth inhibition by mechanical stress. Science 174:961-962. https://doi.org/10.1126/ science.174.4012.961

Vollsinger S, Mitchell SJ, Byrne KE, Novak MD, Rudnicki M (2005) Wind tunnel measurements of crown streamlining and drag relationships for several hardwood species. Can J For Res 35:1238-1249. https://doi.org/10.1139/x05-051

Wagner K, Zotz G (2018) Epiphytic bromeliads in a changing world: the effect of elevated $\mathrm{CO}_{2}$ and varying water supply on growth and nutrient relations. Plant Biol 20:636-640. https://doi.org/10.1111/plb.12708

Warren SD, Black HL, Eastmond DA, Whaley WH (1988) Structural function of buttresses of Tachigalia versicolor. Ecology 69:532-536. https://doi.org/10.2307/1940451

Watson AJ, Tombleson JD (2002) Toppling in juvenile pines: a comparison of the root system characteristics of directsown seedlings, and bare-root seedlings and cuttings. Plant Soil 239:187-196. https://doi.org/10.1023/A: 1015036105630

Yang X, Deng W (2017) Morphological and structural characterization of the attachment system in aerial roots of Syngonium podophyllum. Planta 245:507-521

Zotz G, Laube S (2005) Tank function in the epiphytic bromeliad, Catopsis sessiliflora. Ecotropica 11:63-68

Zotz G, Bogusch W, Hietz P, Ketteler N (2010) Growth of epiphytic bromeliads in a changing world: the effects of $\mathrm{CO}_{2}$, water and nutrient supply. Acta Oecol 36:659-665. https://doi.org/10.1016/j.actao.2010.10.003

Zotz G, Leja M, Aguilar-Cruz Y, Einzmann HJ (2020) How much water is in the tank? An allometric analysis with 205 bromeliad species. Flora 264:151557. https://doi.org/10. 1016/j.flora.2020.151557

Zotz G, Hietz P, Einzmann HJR (2021) Functional ecology of vascular epiphytes. Annual plant reviews. Wiley, Hoboken

Zotz G (2016) Plants on plants-the biology of vascular epiphytes. Switzerland: Springer International Publishing.

Publisher's Note Springer Nature remains neutral with regard to jurisdictional claims in published maps and institutional affiliations. 